\title{
Formação inicial e o valor atribuído à teoria: pesquisa com um grupo de professoras atuantes na rede pública estadual paulista
}

\author{
Initial formation and the importance assigned to the theory: research with a group \\ of teachers working in the public schools of São Paulo (Brazil)
}

\section{Formación inicial y el valor atribuido a la teoría: investigación hecha con un grupo de profesoras en la red pública de enseñanza del estado de São Paulo (Brasil)}

ANOEL FERNADES*

CARlos ANTÔNIO GIOVINAZZO JR.***

\begin{abstract}
RESUMO
Este artigo, com o foco no tema da formação docente, apresenta resultados de pesquisa realizada com professoras atuantes no ciclo I do ensino fundamental da rede pública estadual paulista, tendo como objetivo analisar a relação entre o local onde ocorreu a formação inicial e o valor atribuído à teoria. Com base nas respostas dadas a questionário contendo itens referentes às condições objetivas de trabalho, ao curso de formação inicial e aos conhecimentos práticos e teóricos sobre a educação, é examinado o modo como lidam e se relacionam com conceitos e teorias do campo educacional. Os resultados revelam que os conhecimentos teóricos assimilados na formação inicial ou continuada somente são valorizados se percebidos como passíveis de aplicação imediata e de maneira a resolver os problemas vividos na sala de aula. Também atestam que a formação inicial e a instituição na qual é realizada podem influenciar de modo decisivo a relação que os docentes desenvolvem e mantêm com os conhecimentos teóricos. Verificou-se, ainda, uma tendência de aversão à teoria, já que ela não é incorporada autonomamente ao modo de pensar e à experiência intelectual das professoras.
\end{abstract}

Palavras-chave: Formação docente. Conhecimentos teóricos.

\begin{abstract}
This article focus on the subject of teacher formation and presents research results conducted with teachers of early years of basic education in public schools of São Paulo-Brazil. It analyzes the relationship between where happened the initial formation and the importance assigned to the theory. Based on responses to a questionnaire containing items related to the objective conditions of labor, to the initial formation course and to the practical and theoretical knowledge about education, it is examined as to how they deal and relate to concepts and theories of the educational field. The results indicate that the theoretical knowledge assimilated in the initial or continuing formation are only appreciated if perceived as liable to immediate application and so as to solve the problems faced in the classroom. Also indicate that the initial formation and the institution in which it is performed can influence decisively the relationship that the teachers develop and maintains with the theoretical knowledge. It was finally found a tendency of aversion to the theory, because it is not incorporated autonomously in the way of thinking and in the intellectual experience of the teachers.
\end{abstract}

Keywords: Teacher training. Theoretical knowledge.

\section{RESUMEN}

Este artículo, que está enfocado en el tema de la formación docente, presenta resultados de una investigación realizada con profesoras del ciclo 1 de la red pública de enseñanza primaria del estado de São Paulo, en Brasil, con el objetivo de analizar la relación entre el lugar donde ocurrió la formación inicial y el valor atribuido a la teoría. Basado en las respuestas dadas al cuestionario que contiene elementos relativos a las condiciones objetivas de trabajo, al curso de formación inicial y a los conocimientos prácticos y teóricos sobre la educación, es examinado el modo cómo estas personas tratan y se relacionan con conceptos y teorías del campo educativo. Los resultados indican que los conocimientos teóricos asimilados en la formación inicial o continua son valorados solamente cuando percibidos como susceptibles de aplicación inmediata y con el fin de resolver los problemas experimentados en el aula. También indican que su formación inicial y la institución en la que se lleva a cabo pueden influir decisivamente en la relación que los docentes desarrollan y mantienen con los conocimientos teóricos. También fue verificado que hubo una tendencia a la aversión a la teoría, ya que esta no es incorporada por sí sola a la manera de pensar ni a la experiencia intelectual de los profesores.

Palabras clave: Formación docente. Conocimientos teóricos.

\footnotetext{
*Doutor em Educação: História, Política, Sociedade pela PUC/SP. Professor do Curso de Pedagogia da Faculdade de Itapecerica da Serra. E-mail: <anoelfernandes@ig.com.br>.

**Doutor em Educação e professor do PEPG em Educação: História, Política, Sociedade da PUC/SP. E-mail: <cgiovinazzo@pucsp.br>.
} 


\section{INTRODUÇÃO}

O presente artigo discute a formação de professores. Diante da amplitude de fatores que envolvem a temática, focalizou-se o seguinte objetivo: verificar se o local que ocorreu a formação inicial de um grupo de professoras atuantes no ciclo I da rede pública estadual paulista interfere no valor que atribuem à teoria, tendo como referência a noção de formação tal como formulada por Adorno (1972).

Antes de adentrar nas formulações de Adorno, e na potencialidade de tais formulações como referencial para a análise da formação de professores, destaca-se que, no Brasil, há uma enormidade de linhas de pesquisa sobre a temática da formação de professores, conforme apontado nos balanços de pesquisa realizados por Andrade (2006) e André et al. (1999).

Em seu balanço de pesquisa, Andrade (2006, p. 23) identificou cinco eixos temáticos sobre a formação de professores no país: formação inicial, formação continuada, formação inicial e continuada juntas, identidade e profissionalização docente e política de formação. De sua parte, André et al. (1999) tiveram como objetivo fazer uma síntese integrativa do conhecimento sobre o tema da formação do professor. Tendo como base a análise das dissertações e teses defendidas nos programas de pós-graduação em educação do país (de 1990 a 1996), os artigos publicados em dez periódicos da área (no período 1990-97) e as pesquisas apresentadas no Grupo de Trabalho (GT) Formação de Professores da Associação Nacional de Pós-Graduação e Pesquisa em Educação (Anped) no período de 1992 a 1998. No que diz respeito às dissertações e teses defendidas entre os anos de 1990 e 1996, as autoras destacam que "dos 284 trabalhos sobre formação do professor, produzidos de 1990 a 1996, um total de $216(76 \%)$ tratam do tema da formação inicial, $42(14,8 \%)$ abordam o tema da formação continuada e $26(9,2 \%)$ focalizam o tema da identidade e da profissionalização docente" (ANDRÉ et al. 1999, p. 302). As autoras analisam também um total de 115 artigos publicados no período entre 1990 e 1997, em dez periódicos selecionados, com base nos critérios de expressividade e acessibilidade, e considerando a importância da instituição divulgadora e sua circulação nacional. Os temas mais enfatizados nos periódicos foram "identidade e profissionalização docente, com 33 artigos (28,7\%); formação continuada, com 30 (26\%); formação inicial, com 27 (23,5\%) e prática pedagógica, com 25 (22\%)" (ANDRÉ et al. 1999, p. 304). Quanto ao GT Formação de Professores da Anped, as autoras encontraram 70 trabalhos apresentados no período 199298. Os principais temas abordados nesses textos foram: "Formação inicial, com um total de 29 textos (41\%), formação continuada, com 15 textos (22\%), identidade e profissionalização docente, com 12 textos (17\%), prática pedagógica, com 10 textos (14\%) e revisão de literatura, com 4 textos (6\%)" (ANDRÉ et al., 1999, p. 307). Como reflexão sobre as temáticas de investigação, as autoras ressaltam que "o tema da identidade e profissionalização docente surge como tema emergente nos últimos anos, o que abre perspectivas para questões de grande interesse e atualidade, como a busca da identidade profissional do docente" (ANDRÉ et al. 1999, p. 303).

Ao apontar o que significa identidade e, especificamente, identidade de professores, Pimenta (1997) afirma:

Aidentidade não é um dado imutável. Nem externo, que possa ser adquirido. Mas é um processo de construção do sujeito historicamente situado. A profissão de professor, como as demais, emerge em dado contexto e momento históricos, como resposta a necessidades que estão postas pelas sociedades, adquirindo estatuto de legalidade. Assim, algumas profissões deixaram de existir e outras surgiram nos tempos atuais. Outras adquirem tal poder legal, que se cristalizam a ponto de permanecerem com práticas altamente formalizadas e significado burocrático. Outras não chegam a desaparecer, mas se transformam adquirindo novas características para responderem a novas demandas da sociedade. Este é o caso da profissão de professor. Essas considerações apontam para o caráter dinâmico da profissão docente, como prática social. É na leitura crítica da profissão, diante das realidades sociais, que se buscam os referenciais para modificá-la. No caso da educação escolar, constatamos, no mundo contemporâneo, que ao crescimento quantitativo dos sistemas de ensino não tem correspondido um resultado formativo (qualitativo), adequado às exigências da população envolvida, nem às exigências das demandas sociais, o que coloca a importância de definir nova identidade profissional do professor (1997, p. 6-7).

Não se desconsideram as linhas de pesquisas que têm como foco a apreensão da identidade dos professores. Apesar de reconhecer seu crescimento e importância, o caminho aqui proposto visa a ir além da busca da identidade docente, pois entende-se que, apesar das mudanças apontadas por Pimenta (1997), é necessário relacionar a educação escolar, a prática pedagógica e a formação de professores com as contradições existentes na própria sociedade. Em outras palavras, é fundamental compreender como tais contradições se configuram no exercício da docência, pois, embora seja relevante conhecer o que está implicado na identidade docente, é fundamental não perder de vista os nexos desta com a ordem social, sob pena de entender os professores como os únicos responsáveis pelos problemas da educação. Isso porque não assumem compromissos que fariam parte 
de sua profissão, ou porque não receberam formação (inicial e/ou continuada) adequada. Conforme Pimenta (1997, p. 7), "uma identidade profissional se constrói, pois, a partir da significação social da profissão; da revisão constante dos significados sociais da profissão; da revisão das tradições". Se tal afirmação faz sentido, não pode servir de base para interpretações que revelam que seria suficiente para solucionar os problemas educacionais, incluindo o fracasso escolar, o investimento na formação de professores. De modo que estes se ajustassem às mudanças para que a melhoria na educação acontecesse.

Da perspectiva aqui adotada - a teoria crítica da sociedade -, a formação dos indivíduos, incluindo a profissional, deve ser investigada com base nas contradições que constituem a sociedade, pois, de acordo com Maar (2001, p. 97), "tanto a sociedade, quanto o indivíduo são produzidos no processo de reprodução da formação social vigente". Assim, "o cerne da teoria crítica da sociedade está em apreender a formação como social e em seu processo de reprodução material" (MAAR, 2001, p. 95). As ponderações do autor apontam para a necessidade do exame de variados aspectos relativos à formação de professores. Dentre alguns, podem ser citados aqueles que se referem às condições objetivas a partir das quais acontece a formação inicial e continuada de professores, dando ênfase para o que promove o envolvimento ou o afastamento do professor da docência e de tudo o que está implicado com a atuação na escola pública. Também podem ser enfatizadas as dificuldades e os obstáculos enfrentados na formação e no exercício da profissão.

\section{FORMAÇÃO DE PROFESSORES: CONSIDERAÇÕES A PARTIR DA TEORIA CRÍTICA DA SOCIEDADE}

Como ponto de referência para estabelecer a posição da teoria crítica da sociedade sobre a formação, apresenta-se a definição de Adorno (1972). Ao discorrer sobre o conceito de formação, o autor define-a da seguinte maneira: "La formación no es outra cosa que la cultura por el lado de su apropriación subjetiva" (ADORNO, 1972, p. 142-43). Se isso corresponde à realidade, então, é imprescindível considerar, como ressalta Resende (2003), que a cultura não é independente, quer da sociedade, quer da natureza, quer do indivíduo - categorias privilegiadas na teoria crítica. Conforme a autora, "os nexos estabelecidos entre os conceitos de sociedade, indivíduo, cultura e natureza estão sempre presentes, independentemente de qualquer aspecto que esteja sendo analisado, portanto, seria difícil refletir acerca dessa teoria sem analisar a questão da formação" (RESENDE, 2003, p. 38). De outa parte,
Adorno (1972) enfatiza que o problema da formação é mais abrangente do que possa parecer à primeira vista. Conforme o autor,

Lo que hoy está patente como crisis de la formación cultural ni es mero objeto de la disciplina pedagógica, que tendría que ocuparse directamente de ello, ni puede superarse con uma sociología de yuxtaposiciones precisamente de la formación misma. Los síntomas de colapso de la formación cultural que se advierten por todas partes, aun en el estrato de las personas cultas, no se agotan com las insuficiencias del sistema educativo y de los métodos de educación criticadas desde hace generaciones; las reformas pedagógicas aisladas, por indispensables que sean, no nos valen, y al aflojar las reclamaciones espirituales dirigidas a los que han de ser educados, así como por una cándida despreocupación frente al poderío de la realidade extrapedagógica sobre éstos, podrían más bien en ocasiones, reforzar la crisis (ADORNO, 1972, p. 141-42).

Para os autores da teoria crítica, a cultura não é independente da sociedade, da natureza e do indivíduo. Os nexos estabelecidos entre tais conceitos estão sempre presentes, afora qualquer aspecto que esteja sendo analisado (RESENDE, 2003). Portanto, seria difícil refletir acerca da formação cultural e profissional. Essas duas dimensões não podem ser encaradas como momentos distintos, mas em interconexão - sem analisar o que a promove (ou pode promover) e o que a impede de se realizar. Justifica-se, dessa forma, a afirmação de que para analisar a formação na sociedade contemporânea é necessário compreender a dialética imanente ao processo de reprodução material da sociedade, considerando a forma social em que a formação está circunscrita.

Assim, o colapso da formação, ao qual Adorno se refere, é resultante de um processo social amplo, cujas determinações devem ser apreendidas também fora do âmbito estritamente cultural e pedagógico. Assim, para conhecer o processo de formação, no âmbito da reprodução da vida real dos homens, é necessário investigá-la no conjunto da sociedade em que se manifesta, ou seja, é preciso considerá-la "no plano da própria produção social da sociedade em sua forma determinada" (MAAR, 2003, p. 471).

Horkheimer e Adorno (1973) mencionam que o indivíduo se forma com os outros e com o meio, isto é, na convivência. Os autores são enfáticos no posicionamento sobre o processo formativo, assinalando que este deve estimular o pensamento próprio e a consciência, fatores fundamentais para o desenvolvimento da crítica e, portanto, das possibilidades de agir com autonomia ante as imposições da sociedade. Entretanto, Crochík (2000, p. 163) afirma que a sociedade burguesa privou a formação de sua base, surgindo em seu lugar a pseudoformação, 
que é "a integração e domesticação do indivíduo. (...) a pseudoformação impede o pensamento". Diante dessa situação, a individuação não proporciona a apropriação livre da cultura, prevalecendo o momento da adaptação aos padrões de conduta, de comportamento e de pensamento e a dificuldade de resistir às pressões sociais.

É justamente nas determinações sociais a que são submetidos os indivíduos que recai o interesse deste estudo, a saber: realiza-se a análise sobre a formação inicial e como esta interfere na maneira com a qual um grupo de professoras atuantes no ciclo I do ensino fundamental da rede pública estadual paulista lida com os conhecimentos teóricos.

Adorno (2006), ao refletir sobre a formação de professores, aponta:

A colcha de retalhos formada de declamação ideológica e de fatos que foram apropriados, isto é, na maior parte das vezes decorados, revela que foi rompido o nexo entre objeto e reflexão. A constatação disso nos exames [provas aplicadas nos futuros professores] é recorrente, levando imediatamente a concluir pela ausência da formação cultural (Bildung) necessária a quem pretende ser um formador (ADORNO, 2006, p. 63).

Ao indicar as causas dessa ausência de formação, Adorno (2006, p. 71) assinala que "as condições sociais como a origem, em relação à qual todos são impotentes, são culpadas pela insuficiência do conceito enfático de formação: a maioria não teve acesso àquelas experiências prévias a toda educação explícita de que a formação cultural se nutre". Essas considerações possibilitam a reflexão sobre a realidade brasileira, mais especificamente sobre indivíduos que procuram a formação para o exercício da docência, uma vez que os postulantes a essa função talvez não tenham formação cultural e política necessária para se tornarem formadores. De outro lado, buscam uma ascensão social por meio do exercício da docência, tal como identificado por Penna (2007). Em sua pesquisa, a autora revela que os indivíduos investigados por ela são, na maioria, pertencentes às camadas populares e, por conta disso, o magistério representou a possibilidade de ascensão social, posicionando-os nas classes médias (PENNA, 2007).

As ponderações de Penna (2007), em concomitância com o referencial teórico aqui adotado, convergem para a necessidade de refletir sobre a formação docente sem perder de vista os nexos estabelecidos com outros fatores, entre os quais, para os interesses aqui delineados, a manifestação de professores sobre como lidam com os conhecimentos teóricos. Para Adorno, a teoria tem um papel fundamental na formação. Mas não se trata de simples assimilação de conceitos ou de referências que devem orientar a prática. $\mathrm{O}$ autor considera a relação viva entre a teoria e a práxis social. Assim, de nada adianta o esforço para incorporar o conhecimento teórico se ele não corresponder "(...) à disposição aberta, à capacidade de se abrir a elementos do espírito, apropriando-os de modo produtivo na consciência" (ADORNO, 2006, p. 64). Além disso, a formação depende de outra capacidade: a de realizar experiências. E estas podem ser definidas como a relação do sujeito com o objeto, mas configuradas de maneira a que o sujeito desenvolva a consciência acerca da realidade e de seu conteúdo e que produza a capacidade de relacionar "(...) as formas e estruturas de pensamento do sujeito e aquilo que ele não é" (ADORNO, 2006a, p. 151). Portanto, lidar com a teoria de um modo vivo impõe desenvolver a habilidade de pensamento e "(...) pensar é o mesmo que fazer experiências intelectuais" (ADORNO, 2006a, p. 151). Assim, a maneira com a qual os professores lidaram e os estudantes futuros professores lidam com os conhecimentos teóricos em seus cursos de formação inicial indica muito acerca da formação que receberam e do processo em si.

Não se desconsidera o fato de que o tema da formação docente é muito amplo. Portanto, não se pretendeu dar conta da enorme abrangência que caracteriza a educação escolar, seja ela geral ou profissional. Ciente disso, o foco na formação das professoras ${ }^{1}$ ocorreu visando a verificar se esta determina ou influencia o valor que atribuem aos conhecimentos teóricos.

Decisão que foi tomada em decorrência do entendimento de que a formação docente não se reduz ao aprendizado de técnicas de ensino e de gestão do espaço escolar; além de envolver a apropriação dessas técnicas, também está ancorada em concepções teóricas relacionadas à sociedade, à política, à educação e à economia. Adorno (2006, p. 54), ao tecer ponderações sobre a formação dos futuros professores na Alemanha, considerou que esta deve "(...) ir além do aprendizado profissional estrito (...)". Implica o desenvolvimento da capacidade de “(...) reflexão acerca de sua própria profissão, ou seja, [os professores bem formados] pensam acerca do que fazem, e também refletem acerca de si mesmos". Note-se que o autor ressalta a importância de o professor refletir sobre a profissão e não somente sobre a prática. Em última instância, a autonomia proporcionada pela formação deve incidir, também, sobre a capacidade e sobre o poder político de decidir os rumos da escola e da educação oferecida a crianças, adolescentes e jovens. Essas considerações justificam o estudo dos nexos entre a formação e os conhecimentos teóricos.

\footnotetext{
Doravante, os sujeitos de pesquisa serão denominados de professora(s) Isso porque o grupo é composto somente por indivíduos do sexo feminino.
} 


\section{MÉTOdo E PROCEDIMENTO DE PESQUISA}

Como procedimento de pesquisa, optou-se pela elaboração de um questionário e sua aplicação em um grupo de professoras do ciclo I do ensino fundamental. Este foi composto por questões fechadas e abertas, com as quais se objetivou averiguar as respostas que certos indivíduos dão a determinado questionamento (SELLTIZ et al., 1974). A escolha do questionário como técnica de coleta de informações está associada à complexidade de algumas questões que, por conta disso, demandaram um esforço de pensamento e reflexão dos indivíduos. E é justamente em decorrência da possibilidade de os sujeitos pensarem sobre certos temas que se entendeu razoável a escolha dessa técnica, o que permitiu conhecer como as professoras se posicionam sobre tais temas. Ao apontar as vantagens do questionário, Selltiz et al. (1974, p. 17) afirmam que "este poderá exercer menos pressão sobre o respondente para que dê uma resposta imediata". Ainda acerca da escolha do questionário e da possibilidade de os respondentes pensarem sobre o que é perguntado, preterindo-se outras técnicas de pesquisa, como a entrevista, Selltiz et al. (1987, p. 17) afirmam que

Quando se dá uma ampla margem de tempo aos sujeitos para responderem questões sobre atitudes, eles poderão considerar cuidadosamente cada aspecto da resposta em vez de responder o que lhes vem à mente, como o que ocorre sob a pressão social dos longos períodos de silêncio numa entrevista.

Ressalte-se que, antes da aplicação às professoras que compuseram a amostra, foi realizado um pré-teste para o aperfeiçoamento do instrumento com três outros professores, o que permitiu, posteriormente, realizar alguns ajustes no questionário.

\section{SELEÇÃo dAS ESCOLAS E DAS PROFESSORAS PARA A COMPOSIÇÃO DA AMOSTRA}

Essa pesquisa foi realizada no município de Campinas (SP), em escolas da rede pública estadual. Diante da impossibilidade de investigar os professores presentes em todas as escolas do município, alguns critérios foram adotados para a seleção dos indivíduos que fizeram parte da amostra. O primeiro deles visou à delimitação da região e do ciclo de ensino no qual os professores atuam.

A seleção das escolas foi baseada na divisão regional do município e na divisão das diretorias de ensino. Geograficamente, Campinas é dividida em seis regiões: Central, Norte, Leste, Sul, Oeste e Noroeste. No que diz respeito às escolas públicas estaduais, o munícipio possui duas diretorias de ensino (Leste e Oeste). Um fato a ser destacado é que no processo de divisão das escolas entre as duas diretorias não foi tomada como critério nenhuma delimitação geográfica. O que ocasionou a distribuição das escolas de quase todas as regiões de Campinas em ambas as diretorias. Embora essa distribuição não tenha sido feita em função da localidade em que estas se encontram, observa-se uma particularidade na região Noroeste: suas escolas pertencem à diretoria de ensino região Campinas Oeste (Derco). Por conta disso, essa diretoria foi selecionada para a pesquisa. A definição não ocorreu porque diretoria de ensino e região da cidade coincidem quando se olha para a localização das escolas, mas em razão da diversidade encontrada. A Derco é composta por 94 escolas, sendo 84 localizadas no próprio município de Campinas, sete em Valinhos e três em Vinhedo. As escolas de Vinhedo e Valinhos possuem a peculiaridade de atenderem somente ao ciclo II do ensino fundamental ( $6^{\circ}$ ao $9^{\circ}$ ano) e ao ensino médio, cabendo à Rede Municipal de Educação desses municípios oferecer o ciclo I (antiga $1^{\underline{a}}$ a $4^{\underline{a}}$ série; atualmente, $1^{\circ}$ ao $5^{\circ}$ ano). Esse fato exclui tais escolas porque - como será justificado mais adiante - foram investigados somente professores atuantes no ciclo I. Dessa forma, só as unidades escolares localizadas no município de Campinas constituíram a base para a seleção das escolas e, por conseguinte, dos sujeitos investigados. Das 84 escolas da Derco situadas em Campinas, 55 atendem ao ciclo I do ensino fundamental.

Tendo em vista o grande número de escolas (55), optou-se por investigar sujeitos de todas as escolas pertencentes à Derco e situadas na região Noroeste de Campinas. Tal escolha está associada ao fato de que essas escolas, além de pertencerem à mesma diretoria de ensino - o que não ocorreria se a investigação se verificasse em alguma outra região -, também possuem a peculariedade de estarem localizadas em uma região caracterizada como periférica, seja pela distância da região central, seja pelas condições socioeconômicas da população atendida. Sendo assim, as professoras que fizeram parte da amostra atuam na região Noroeste de Campinas, que, por sua vez, possui 16 escolas da rede pública estadual. Desse total, 10 atendem ao ciclo I do ensino fundamental.

\section{Procedimentos de COLETA de dAdos}

Para a aplicação do questionário, o pesquisador foi à Derco, apresentou o questionário e o Termo de Consentimento Livre e Esclarecido e, posteriormente, solicitou ao dirigente de ensino uma carta de apresentação para ser levada nas escolas. Em seguida, foi até as escolas selecionadas com o intuito de agendar um dia para visita no Horário de Trabalho Pedagógico Coletivo (HTPC) a fim de realizar, nesse momento, a coleta dos dados.

Ressalte-se que, quando da aplicação do questionário, o pesquisador esteve junto com as professoras para 
elucidar possíveis dúvidas referentes ao entendimento do enunciado das questões. Dessa forma, o questionário foi aplicado - entre os meses de setembro e novembro de 2012 -, nas 10 escolas, para as professoras que, após o pesquisador apresentar a pesquisa, aceitaram participar. $\mathrm{O}$ fato de estar junto com os sujeitos de pesquisa não implicou nenhum prejuízo para a confiabilidade das informações. Isso porque a intervenção ocorreu somente com o intuito de esclarecer dúvidas a respeito do questionário e não para emitir opiniões sobre as temáticas apresentadas.

Para garantir os princípios éticos que envolvem a pesquisa com seres humanos, o pesquisador entregou aos sujeitos, e leu com eles, o Termo de Consentimento Livre e Esclarecido. Assim, a aplicação do questionário só ocorreu após autorização e consentimento por escrito das professoras envolvidas. Além disso, o pesquisador assumiu o compromisso de manter absoluto e total sigilo e confidencialidade em relação à identidade dos sujeitos e das informações fornecidas.

Um fator a ser destacado diz respeito à dificuldade de acesso às unidades escolares e, por conseguinte, de adesão das professoras. Os Horários de Trabalhos Pedagógicos Coletivos (HTPC) nas escolas onde estão situados os sujeitos que fizeram parte da amostra ocorrem em dois dias da semana. Em alguns casos, o grupo de professoras é dividido e as reuniões acontecem em dias distintos. Por conta disso - e devido à dispensa das professoras ter sido autorizada pelo dirigente de ensino somente em uma reunião de HTPC -, a apresentação do questionário foi feita a 73 professoras. Desse total, 37 aderiram à pesquisa.

\section{O VALOR DA TEORIA NAS PERCEPÇÕES DAS PROFESSORAS}

A definição do ponto de partida para se conhecer como as professoras lidam com os conhecimentos teóricos está assentada em dois fatores. O primeiro refere-se ao pressuposto de que a valorização dada à teoria possui inter-relação com os conhecimentos e percepções que possuem da educação. Já o segundo fator está vinculado à hipótese que considera a influência do curso e da instituição onde realizaram a formação inicial na relação que estabelecem com a teoria. Apresenta-se a seguir a Tabela 1, que identifica as instituições de formação inicial das professoras investigadas.

Tabela 1. Professoras da amostra segundo instituição de formação

\begin{tabular}{lcc}
\hline A instituição de formação foi & Quantidade & Proporção \\
\hline Pública & 3 & 0,08 \\
Privada & 34 & 0,92 \\
Total & 37 & 1,00 \\
\hline
\end{tabular}

Pode-se notar a grande diferença entre o número de professoras que se formaram em instituições privadas - 34 - em relação às que se formaram em instituições públicas - somente três professoras. A análise do tipo de instituição de formação das professoras pôde ser feita a partir do cotejamento dos números encontrados com os dados apresentados por Francisco (2010): ao investigar 125 professores do ensino médio da rede pública estadual paulista - sendo 22 formados em universidades públicas e 103 em instituições privadas -, o autor constatou que os professores formados nas primeiras apresentaram maior inclinação para a resistência às imposições feitas pela Secretaria de Estado da Educação-SP (SEE/SP) do que os graduados nas segundas. É claro que não se pode tomar esses dados e transferi-los diretamente para as professoras investigadas. Mas é possível refletir sobre o poder que a formação inicial possui no oferecimento de referências aos professores, de modo que possam desenvolver uma postura mais autônoma quando do exercício da profissão.

Nessa linha de reflexão foi proposta uma questão aberta para as professoras apontarem as teorias pedagógicas ou autores que recordam ter estudado na formação inicial ou continuada. Libâneo (1990) classifica as tendências pedagógicas (e seus autores) em dois grupos: liberais e progressistas. No primeiro grupo, estão incluídas as tendências tradicional, renovada progressivista, renovada não diretiva e tecnicista. No segundo, as tendências libertadora, libertária e crítico-social dos conteúdos. A classificação proposta por Libâneo (1990) não foi objeto de análise, e não foi verificado se as professoras conhecem as teorias de acordo com essa classificação, mas sim os conhecimentos teóricos e autores que são capazes de mencionar. As definições de Libâneo servem apenas como indicativo das teorias pedagógicas presentes no debate educacional. Das 37, somente 23 professoras responderam à questão proposta. Os dados estão dispostos na Tabela 2.

Embora no enunciado da questão houvesse a sugestão para que as professoras se manifestassem sobre os autores e teorias mencionadas, destaque-se que nenhuma fez isso. Resssalte-se também o fato de que, das 37 professoras, somente 23 responderem à questão, o que em síntese pode ser indicador da dificuldade de se expressarem sobre autores ou teorias. Em um total de 113 citações, temos 27 autores diferentes. Entre os cinco autores mais citados, verifica-se forte presença da Psicologia (Piaget, com 22 menções, seguido de Vygotsky, com 18, Emília Ferreiro, com 15, e Wallon, com oito). Somente um autor que formulou teoria educacional aparece: Paulo Freire, com 13 menções. É bem verdade que Emília Ferreiro também é referência para as práticas de alfabetização, mas a base é a Psicologia. 
Tabela 2. Autores ou teorias lembradas pelas professoras investigadas

\begin{tabular}{lcc}
\hline \multicolumn{1}{c}{ Autores/teorias } & Quantidade & \% \\
\hline Piaget & 22 & 19,5 \\
Vygotsky & 18 & 16 \\
Emília Ferreiro & 15 & 13 \\
Paulo Freire & 13 & 11,5 \\
Wallon & 8 & 7 \\
Jussara Hoffman & 7 & 6,2 \\
Perrenoud & 5 & 4,4 \\
Ana Teberosky & 3 & 2,6 \\
Constance Kamii & 2 & 1,8 \\
Luís Carlos Cagliari & 2 & 1,8 \\
Telma Weisz & 2 & 1,8 \\
Ana Lúcia Goulart & 1 & 0,9 \\
Aries & 1 & 0,9 \\
Freinet & 1 & 0,9 \\
Gramsci & 1 & 0,9 \\
Ives de La Taille & 1 & 0,9 \\
Libâneo & 1 & 0,9 \\
Luiz Carlos de Freitas & 1 & 0,9 \\
Madalena Freire & 1 & 0,9 \\
Magda Soares & 1 & 0,9 \\
Marx & 1 & 0,9 \\
Manacorda & 1 & 0,9 \\
Montessori & 1 & 0,9 \\
Orly Mantovani & 1 & 0,9 \\
Saviani & 1 & 0,9 \\
Telma Vinha & 1 & 0,9 \\
Weber & & 100 \\
Total & 13 & \\
\hline & & \\
& 1 & \\
\hline
\end{tabular}

Outras duas questões visaram à apreensão da relação das professoras com teorias e autores. Ao serem questionadas sobre qual(is) desses autores citados estão mais próximos daquilo que pensam sobre escola e educação, 20 professoras responderam à questão. Os dados foram associados às instituições de formação inicial das professoras e são apresentados na Tabela 3.
Entre as 20 professoras que responderam à questão, somente três se formaram em instituições públicas e as outras 17 se formaram em instituições privadas. Mesmo sendo em número bem menor, as professoras formadas em instituições públicas citaram muito mais autores: três professoras conseguiram se lembrar de 11 autores, enquanto 17 conseguiram se lembrar de apenas cinco. Embora se reconheça que isso pode ter acontecido em razão de uma diversidade de fatores, tal dado permite inferir que a instituição de formação inicial pode influenciar no repertório de autores conhecidos pelas professoras. Ao serem questionadas sobre por que tais autores estão mais próximos do que pensam sobre escola e educação, somente 17 professoras responderam à questão, sendo duas formadas em instituições públicas e 15 em instituições privadas. A seguir, são apresentadas as manifestações das professoras, que estão numeradas para facilitar a identificação; ao final das respostas, indicam-se os autores sobre os quais as manifestações se referiam, além da instituição de formação inicial.

1 - Auxilia na sala de aula na questão da escrita (Emília Ferreiro - instituição privada).

2 - O processo de aprendizagem pelo qual a criança passa é muito bem explorado por eles (Piaget e Vygotsky - instituição privada).

3 - Porque concebe o desenvolvimento humano a partir das relações sociais que a pessoa estabelece no decorrer da vida. E o processo de ensino-aprendizagem se constitui de interações e contextos sociais. É o que está mais dentro do que trabalhamos em sala de aula (Vygotsky - instituição privada).

4 - Acredito no construtivismo e nas hipóteses de aquisição de aprendizagem (Piaget e Emília Ferreiro - instituição privada).

Tabela 3. Autores explicitados como mais relevantes e a instituição de formação das professoras investigadas

\begin{tabular}{lccc}
\hline $\begin{array}{c}\text { Autores mais próximos das } \\
\text { concepções das professoras } \\
\text { sobre educação }\end{array}$ & $\begin{array}{c}\text { Formação inicial em } \\
\text { instituições públicas } \\
\text { (três professoras) }\end{array}$ & $\begin{array}{c}\text { Formação inicial em } \\
\text { instituições privadas } \\
\text { (17 professoras) }\end{array}$ & $\begin{array}{c}\text { Número de vezes que } \\
\text { o autor foi citado }\end{array}$ \\
\hline Piaget & 3 & 7 & 10 \\
Vygotsky & 3 & 7 & 10 \\
Emília Ferreiro & 3 & 4 & 7 \\
Paulo Freire & 3 & 1 & 4 \\
Wallon & 2 & - & 2 \\
Ana Teberosky & 1 & 1 & 2 \\
Constance Kamii & 1 & - & 1 \\
Luís Carlos Cagliari & 1 & - & 1 \\
Marx & 1 & - & 1 \\
Saviani & 1 & . & 1 \\
Telma Vinha & 1 & 20 & 40 \\
Total de respostas & 20 & & 1 \\
\hline
\end{tabular}

* Nenhuma vez mencionado. 
5 - Auxiliam na linguagem, compreensão e competências, diversidades e desenvolvimento da aprendizagem da criança (Emília Ferreiro, Piaget instituição privada).

6 - Porque auxiliam a compreender a linguagem, as competências e o desenvolvimento (Emília Ferreiro, Piaget - instituição privada).

7 - Porque ele desenvolveu um trabalho voltado para o desenvolvimento do aluno (Piaget - instituição privada).

8 - Alfabetização e letramento. Construção do conhecimento (Emília Ferreiro e Piaget - instituição privada).

9 - Fala sobre o cognitivo de como a criança aprende, defende o construtivismo, acrescentando saberes aos seus conhecimentos prévios (Vygotsky instituição privada).

10 - Acredito que contribua muito na forma de ensinar, na relação de educadores e educandos (Paulo Freire - instituição privada).

11 - Porque fez pesquisas com seres humanos e ajudou a decifrar como as crianças aprendem (Piaget - instituição privada).

12 - Valorização do ser que constrói seu conhecimento dentro do contexto em que vive (Vygotsky instituição privada).

13 - Porque nele existe uma interação entre aluno e professor, e aluno e aluno, produzindo conhecimento, sendo o papel do professor mais ativo (Vygotsky e Piaget - instituição privada).

14 - Porque segundo o autor a criança aprende com o meio (Vygotsky - instituição privada).

15 - Emília Ferreiro, pois ela trata da parte da alfabetização (Emília Ferreiro - instituição privada).

16 - Porque eles são contrários à educação mercantilizada e usada como jogo político que realmente não está a serviço da população, porque não temos condições físicas, financeiras, estruturais e espaços fisicos adequados para desenvolver um bom trabalho. Temos: 19) salas lotadas (35-40) de alunos do $1^{\circ}$ ao $5^{\circ}$ ano; 2 ) salário aviltante; 3 ) trabalhamos em mais de uma escola; 4o) políticas da Secretaria da Educação (classificatória e excludente) através da bonificação por resultados; 5o) desvalorização e degradação da figura do professor e da escola pública (Marx, Saviani, Luís Carlos de Freitas e Paulo Freire instituição pública).

17 - Gosto muito das ideias do Marx sobre o sistema capitalista na qual a escola está inserida e também da forma que Piaget avalia o desenvolvimento moral (Marx, Piaget - instituição pública).
A relação de autores mencionados e os motivos de opção por uns ou outros possuem algumas particularidades. Entre as quais, a baixa incidência de respostas às questões abertas, uma vez que, das 37 professoras, somente 17 relacionaram autores, escola e educação. No que tange especificamente à relação que fazem com os autores a quem referenciaram, das 17 , apenas as respostas de números 16 e 17 fizeram alguma alusão aos autores, relacionando-os com aspectos políticos e sociais. Destaca-se a primeira: ao apontar os autores que mais a influenciam, a professora fez alusão direta às condições de trabalho na rede pública estadual paulista. Conforme explicitado, ressalta-se que a formação dessas duas professoras ocorreu em instituições públicas, e suas respostas destoam das demais, uma vez que, de forma geral, ao estabelecerem a relação dos autores com as suas concepções de educação, voltaram-se unicamente para a solução de questões pedagógicas do dia a dia da sala de aula.

Vale lembrar que não se esperava que as professoras associassem a utilidade da teoria com suas práticas. $\mathrm{O}$ que se pretendeu realizar foi o exame do valor atribuído aos conhecimentos teóricos por meio dos autores mencionados. Dito de outro modo, é fundamental refletir sobre a fraca relação das professoras - com predominância das formadas em instituições privadas - com a teoria. Quando isso acontece, quer dizer, quando há relação, esta fica restrita predominantemente à possibilidade de a teoria contribuir com a solução dos problemas imediatos enfrentados na sala de aula. Essa situação pode ser cotejada com as ponderações de Adorno (1995), presentes no texto Notas marginais sobre teoria e práxis. Conforme o autor, a transformação da teoria em instrumento de ação imediata desde seu princípio proclamou "como critério de conhecimento a utilidade prática deste, [assim] compromete-o com a situação existente" (ADORNO, 1995, p. 202-03). Ante a reflexão de Adorno sobre o uso pragmático da teoria e a tendência das professoras formadas em instituições privadas de relacionarem a utilidade da teoria quase exclusivamente a questões voltadas para a sala de aula, pode-se afirmar que, de certa forma, verifica-se a refutação dos conhecimentos que não são aplicáveis imediatamente na prática pedagógica. Assim, a teoria é pouco valorizada - e, quando isso acontece, as professoras esperam dela respostas para os problemas que enfrentam com os alunos.

Essa situação tem sua história, e essa busca por solução "aqui e agora" legitima o funcionamento da estrutura tal como determinada pelo sistema social e educacional, pois, conforme destaca Marcuse (1967, p. 175), em relação às condições repressivas as quais os indivíduos estão sujeitos, "o pensamento e qualquer modo de pensar está restrito à orientação pragmática". Por sua vez, 
Adorno (1995, p. 203), ao se referir à utilidade que a teoria poderia ter, enfatiza que

[se] a teoria - para a qual está em jogo a totalidade, se ela não for inútil - ficar amarrada ao seu efeito útil aqui e agora, acontecer-lhe-á o mesmo, apesar da crença de que ela escapa à imanência do sistema. A teoria só se libertaria desta imanência onde se desprendesse das cadeias do pragmatismo, por mais modificadas que elas estejam.

Dessa forma, a simples valorização da teoria, tendo em vista sua aplicabilidade prática, não garante a capacidade de pensar criticamente ou, ainda, de seguir na contramão daquilo que a ordem vigente impõe. Ao vincular estreitamente os conhecimentos teóricos com a prática da sala de aula, as professoras formadas em instituições privadas ficam restritas ao útil para o aqui e agora. Por conseguinte, não os utilizam como ferramenta para a reflexão sobre o sistema, sobre as condições de trabalho e sobre a própria profissão docente - o que foi feito, em certa medida, por pelo menos uma das professoras formadas em instituição pública.

\section{CONSIDERAÇÕES FINAIS}

Com o presente artigo, objetivou-se identificar se o local em que ocorreu a formação inicial de um grupo de professoras atuantes no ciclo I do ensino fundamental da rede pública estadual paulista interfere no valor que atribuem à teoria. Como método de pesquisa foi aplicado um questionário a 37 professoras, das quais três formadas em instituições públicas e 34 em instituições privadas. Tendo como referência as formulações de Adorno, no que diz respeito aos nexos entre a formação e a apropriação de conhecimentos teóricos, verificou-se que o modo pelo qual as três professoras formadas em instituição pública de ensino superior estabelecem relação com a teoria parece ser menos utilitário do que o demonstrado pelas outras 34 professoras.

Os dados apresentados podem não ser definitivos, pois outros aspectos da formação poderiam ser considerados, o que fugiria do escopo deste trabalho. Assim, informações sobre o tempo que os professores dedicam para o estudo, sobre o preparo de aulas e sobre o que estudam podem contribuir com o conhecimento acerca das situações vividas na profissão e que configuram as condições de formação continuada. Do mesmo modo, considerar a rotina diária e a carga de trabalho dos professores (número de aulas dadas por semana, quantidade de turmas e unidades escolares em que exercem a docência, obrigações domésticas e sociais que cumprem, dificuldades materiais que enfrentam, etc.) também pode evidenciar em que condições o magistério está sendo exercido. Fatores que podem interferir nos processos formativos. Observa-se que a elaboração de propostas que visem a promover a formação de professores não pode prescindir de levar em conta a situação na qual eles vivem (atual e futura). Já que existe uma relação direta entre a própria formação, que, como se destacou, engloba a habilitação profissional e a educação política, e as condições objetivas de trabalho e de vida. De nada adianta oferecer aos professores cursos e outras experiências, por mais bem estruturados que sejam, se não for alterada a situação precária e deficitária na qual muitos se encontram na escola e fora dela.

De qualquer maneira, longe de afirmar categoricamente - sem outros estudos que possam pôr à prova a hipótese suscitada neste artigo sobre as professoras investigadas - que as formadas em instituições públicas possuem maior arcabouço teórico em comparação com as formadas em instituições privadas, não se podem desprezar os indicadores. Estes parecem expressar uma tendência importante entre os professores: o que os mobiliza são menos os problemas estruturais da escola brasileira e que fazem com que a luta pela qualidade da educação continue necessária, e mais as urgências impostas pelo dia a dia da sala de aula. Diante da situação na qual os alunos apresentam dificuldades de aprender ou de se envolver com a escola, diante dos parcos recursos materiais e didático-pedagógicos disponíveis, os quais impõem a busca por soluções criativas, os professores são condenados a tratar todos os problemas sem a indispensável consideração pelos fatores sociais, políticos e econômicos que determinam as práticas educacionais.

Por fim, os dados acerca da pequena amostra de professoras revelam que o curso de formação inicial e a instituição na qual este é realizado podem influenciar de modo decisivo a relação que os docentes desenvolvem e mantêm com os conhecimentos teóricos. Basta, para observar esse fato, cotejar os autores que citam e os elementos destacados e atribuídos a tais autores. Verificou-se, ainda, uma tendência de aversão à teoria, já que esta não é incorporada autonomamente ao modo de pensar e à experiência intelectual, imperativos de todo e qualquer processo de formação que mereça esse nome.

\section{REFERÊNCIAS}

ADORNO, Theodor W. Teoría de la seudocultura. In: ADORNO, Theodor W. Filosofía y syperstición. Madrid: Alianza Editorial, 1972, p. 141-174.

ADORNO, Theodor W. Notas marginais sobre teoria e práxis. In: Palavras e sinais: Modelos Críticos 2. Tradução de Maria Helena Ruschel. Petrópolis. Rio de Janeiro: Editora Vozes, 1995.

ADORNO, Theodor W. A filosofia e os professores. In: ADORNO, Theodor W. Educação e emancipação. Rio de Janeiro: Paz e Terra, 2006, p. 51-74. 
ANDRADE, Roberta Rotta Messias de. A formação de professores nas dissertações e teses defendidas em programas de educação entre os anos de 1999 e 2003. Dissertação (Mestrado em em Educação: Psicologia da Educação) Pontifícia Universidade Católica de São Paulo, São Paulo, 2006.

ANDRÉ, Marli Eliza Dalmazo Afonso et al. Estado da arte da formação de professores no Brasil. Educação e Sociedade, Campinas, ano XX, n. 68, p. 301-309, 1999.

CROCHÍK. José Leon. La pseudoformacion y la consciência ilusionada. Revista Educação 26 y Pedagogia 27, Colombia, Universidade de Antioqua/Faculdade de Educación, v. VII, 2000 .

CROCHÍK, José Leon. Notas sobre trabalho e sacrifício. Trabalho, Educação e Saúde, v. 1, n. 1, p. 61-73, 2003. https:/ doi.org/10.1590/S1981-77462003000100006

FRANCISCO, Eduardo. Formação e trabalho docente: um estudo com professores do ensino médio. Dissertação (Mestrado em Educação: história, política, sociedade) - Pontifícia Universidade Católica de São Paulo, São Paulo, 2010.

HORKHEIMER, Max; ADORNO, Theodor. Temas básicos de Sociologia. São Paulo: Cultrix, 1973.

LIBÂNEO, José Carlos. Democratização da escola pública. São Paulo: Loyola, 1990.
PENNA, Marieta Gouvea de Oliveira. Professores de séries iniciais do ensino fundamental em escolas públicas estaduais de São Paulo: posições sociais e condições de vida e trabalho. Tese (Doutorado em Educação: história, política, sociedade) Pontifícia Universidade Católica de São Paulo, São Paulo, 2007.

PIMENTA, Selma Garrido. Formação de professores - saberes da docência e identidade do professor. Revista da Educação da AEC do Brasil, São Paulo, n. 104, p. 45-61, 1997.

MAAR, Wolfgang Léo. Da subjetividade deformada à semiformação como sujeito. Psicologia \& Sociedade, v. 13, n. 2, p. 92-141, jul./dez. 2001.

MAAR, Wolfgang Léo. Adorno, Semiformação e educação. Educação e Sociedade, Campinas, v. 24, n. 83, p. 459-475, 2003. https:/doi.org/10.1590/S0101-73302003000200008

RESENDE, Maria do Rosário. A educação com base em uma formação para a emancipação: uma reflexão. Inter-Ação: Revista da Faculdade de Educação da UFG, Goiânia, p. 37-49, 2003

SELLTIZ, Claire et. al. Métodos de pesquisa nas relações sociais. Tradução de Dante Moreira Leite. 4⿳⺈冂a reimpr. São Paulo: EPU, 1974.

Submetido em 01/07/2015

Aprovado em 08/06/2016 